\title{
ESPÉCIES EXÓTICAS INVASORAS NA ARBORIZAÇÃO DE VIAS PÚBLICAS DE MARINGÁ-PR
}

\author{
Christopher Thomas Blum ${ }^{1}$, Marília Borgo $^{2}$, André Cesar Furlaneto Sampaio $^{3}$
}

(recebido em 26.03.2008 e aceito para publicação em 10.06.2008)

\begin{abstract}
RESUMO
Apesar da temática das espécies exóticas invasoras ser recente no meio científico, e praticamente desconhecida pela sociedade, a invasão biológica desencadeada por elas é a segunda maior causa de perda da biodiversidade no planeta. Quando introduzidas em novos ambientes, elas adaptam-se e ocupam agressivamente o espaço de espécies nativas, produzindo desequilíbrios muitas vezes irreversíveis. Este estudo procurou avaliar o contexto das espécies exóticas na arborização de vias públicas de Maringá. A análise baseou-se nos dados do Projeto Árvore - Censo Verde de Maringá, que cadastrou cerca de 90\% das árvores encontradas na arborização. Constatou-se que, das 87 espécies registrados, apenas $24,1 \%$ são nativas da Floresta Estacional Semidecidual, bioma onde se insere Maringá. As demais são oriundas de outras formações vegetacionais do Brasil $(20,6 \%)$ ou de outros países $(55,2 \%)$. Dezesseis $(18,4 \%)$ espécies exóticas registradas têm potencial de invasão, destacando-se Hovenia dulcis, Leucaena leucocephala, Melia azedarach e Tecoma stans como as que possuem maior capacidade de invasão biológica, dispersando-se vigorosamente a partir das vias públicas, através de florestas ciliares e áreas degradadas. Em futuros planejamentos de manejo da arborização deverá ser prevista a substituição gradativa destas espécies por outras, preferencialmente nativas da região.
\end{abstract}

Palavras-chave: Invasão Biológica, Arborização Urbana, Biodiversidade

\footnotetext{
${ }^{1}$ Engenheiro Florestal, Doutorando em Engenharia Florestal, UFPR, Curitiba, PR blumct@gmail.com

${ }^{2}$ Bióloga, Doutoranda em Engenharia Florestal, UFPR, Curitiba, PR - maborgo@yahoo.com

${ }^{3}$ Engenheiro Florestal, Mestrado em Geografia, UEM, Maringá-PR - sampaio.andre@gmail.com
} 


\title{
INVASIVE ALIEN SPECIES AS URBAN TREES IN THE STREETS OF MARINGÁ
}

\begin{abstract}
Despite the theme of invasive alien species is new to the academy, and virtually unknown by society, the biological invasion caused by these species is the second largest cause of biodiversity loss in the world. This process produces irreversible changes in the environment, as the alien plants occupy the biological position of native species in the plant community. This research was carried out to assess the conditions of alien species as urban trees in the streets from Maringá. We used data from "Tree Project - Maringá Green Census", where $90 \%$ of urban trees in the streets were evaluated. We found 87 tree species. Only $24,1 \%$ of them were native from the Subtropical Semideciduous Forest, the original biome of Maringá. The remaining species were alien plants, coming from other Brazilian forests (20.6\%) or from other countries (55.2\%). Sixteen alien species (18.4\%) were considered invasive. Hovenia dulcis, Leucaena leucocephala, Melia azedarach and Tecoma stans showed the highest potential of biological invasion by spreading themselves vigorously through urban parks, riparian forests and on degraded areas. In the near future, new urban tree planting management plans should consider the gradual replacement of these invasive alien species by native plants, to minimize their environmental threat.
\end{abstract}

Key Words: Biologic Invasion, Urban Trees, Biodiversity 


\section{INTRODUÇÃO}

Maringá até hoje usa como propaganda o fato de ser muito arborizada e possuir belos parques. Atraiu muitos turistas e habitantes pela boa qualidade de vida e, até hoje, se beneficia por ter tido uma iniciativa ambientalmente mais adequada do que a de muitas cidades brasileiras. Durante muitos anos a Companhia Melhoramentos do Paraná - CMNP assumiu a responsabilidade de administrar a arborização da cidade, sem ônus para a administração pública. As mudas eram adquiridas na Secretaria de Agricultura de São Paulo, na Escola Superior de Agricultura "Luiz de Queiroz" de Piracicaba e no Instituto Agronômico de Campinas. À medida que a Prefeitura foi se estruturando passou a assumir essa responsabilidade criando um departamento denominado de Parques e Jardins (SAMPAIO, 2006).

Este histórico de preocupação com a arborização urbana garantiu à Maringá uma situação privilegiada em que árvores contribuem para um aspecto paisagístico urbano mais agradável, trazendo também outros benefícios ambientais como sombreamento, amenização da temperatura, melhorias na qualidade do ar e redução da poluição sonora.

Deve ser ressaltado ainda que, além dos benefícios diretos trazidos ao homem, a arborização de cidades pode também desempenhar importante função ecológica salvaguardando a identidade biológica regional. Para tal devem ser valorizadas as espécies vegetais que ocorrem naturalmente em cada região. De acordo com os autores, é também função ecológica da arborização urbana o fornecimento de abrigo e alimentação à fauna autóctone, viabilizando em parte a vida silvestre no interior das cidades (DANTAS e SOUZA, 2004).

De fato, quando implantadas de forma planejada, árvores na paisagem urbana tendem a proporcionar somente benefícios. Exceção deve ser feita àquelas espécies que tem capacidade de realizar invasão biológica, denominadas atualmente "exóticas invasoras".

Invasão biológica é o processo de introdução e adaptação de espécies que não fazem parte, naturalmente, de um dado ecossistema, mas que se naturalizam e passam a provocar mudanças em seu funcionamento (ZILLER, 2000).

Espécies exóticas são aquelas que ocorrem numa área fora de seu limite natural historicamente conhecido, como resultado de dispersão acidental ou intencional através de atividades humanas (INSTITUTO DE RECURSOS MUNDIAIS; UNIÃO MUNDIAL PARA A NATUREZA; PROGRAMA DAS NAÇÕES UNIDAS PARA O MEIO AMBIENTE, 1992).

Por fim, espécies exóticas invasoras são organismos que, uma vez introduzidos em um novo ambiente a partir de outras regiões, se estabelecem e passam a desenvolver populações auto-regenerativas a ponto de ocupar o espaço de espécies nativas e 
proporcionar alterações nos processos ecológicos naturais, tendendo a tornar-se dominantes e podendo causar impactos ambientais e sócio-econômicos negativos (ZILLER, 2000; ZALBA, 2006; MMA, 2006; PITELLI, 2007).

As espécies exóticas invasoras são consideradas a segunda maior causa de extinção de espécies no planeta, afetando diretamente a biodiversidade, a economia e a saúde humana. Reconhecendo a importância do problema causado pelas invasões biológicas, a Convenção sobre a Diversidade Biológica - CDB estabeleceu, em seu Artigo 8, que país signatário deve, na medida do possível e conforme o caso, impedir a introdução, controlar ou erradicar as espécies exóticas invasoras que ameaçam ecossistemas, habitats e espécies nativas (MMA, 2006).

Nos últimos anos, um processo poderoso tem modificado de forma definitiva a distribuição de espécies no planeta. Os seres humanos têm desempenhado o papel principal destas mudanças. Ao longo da história, a humanidade tem transportado milhares de espécies para fora de suas regiões de ocorrência natural, por diversos motivos. Muitos animais e plantas foram e ainda são movidos propositalmente, com intenção de assegurar segurança alimentar, disponibilidade de combustível e materiais de construção, entre várias outras necessidades humanas.(ZALBA, 2006)

É importante salientar que, à medida que as espécies exóticas introduzidas conseguem estabelecer populações auto-sustentáveis, passam a ser chamadas espécies estabelecidas. Finalmente, algumas das espécies estabelecidas tornam-se aptas a avançar sobre ambientes naturais e alterados, transformando-se em espécies exóticas invasoras. Desta forma, uma exótica invasora é uma espécie introduzida que se propaga, sem o auxílio do homem, e passa a ameaçar ambientes fora do seu território de origem, causando impactos ambientais e sócio-econômicos (ZALBA, 2006).

Desta forma, o presente estudo teve como objetivo avaliar a questão das espécies exóticas invasoras na arborização de vias públicas de Maringá, no sentido de alertar para esta problemática que pode trazer grandes prejuízos para o meio ambiente regional e para a própria sociedade.

\section{MATERIAIS E MÉTODOS}

\section{Área de estudo}

O município de Maringá situa-se na região noroeste do Paraná, entre as coordenadas $23^{\circ} 15^{\prime} 15^{\prime \prime}$ e $23^{\circ} 33^{\prime} 27^{\prime \prime}$ de latitude sul e $51^{\circ} 50^{\prime} 05^{\prime \prime}$ e $52^{\circ} 05^{\prime} 59^{\prime \prime}$ de longitude oeste (BARROS et al., .2004). 
O clima predominante na região de Maringá, segundo a classificação de Köeppen (1978), é do tipo Cfa - subtropical úmido mesotérmico, definido geograficamente pelo traçado do trópico de Capricórnio, na sua região norte (MAACK, 1968).

De acordo com o delineamento de Maack (1968) e adotando o Sistema FisionômicoEcológico de Classificação da Vegetação Brasileira, proposto por Veloso e Goes-Filho (1982), o município de Maringá-PR enquadra-se na região fitogeográfica denominada Floresta Estacional Semidecidual. Este tipo florestal tem como característica encontrar-se condicionado a uma dupla estacionalidade climática. Ocorre em áreas com uma estação climática tropical, que apresenta período de intensas chuvas de verão seguida por estiagem acentuada e outra estação subtropical sem período seco, mas com seca fisiológica provocada pelo intenso frio do inverno, de temperaturas médias inferiores a $15^{\circ} \mathrm{C}$. Neste tipo de vegetação a porcentagem das árvores caducifólias no conjunto florestal situa-se entre 20 a 50\% da cobertura superior da floresta, de onde origina-se sua designação semidecidual. A Floresta Estacional Semidecidual ocorre geralmente sobre solos derivados dos derrames basálticos, predominantemente nas altitudes inferiores a $600 \mathrm{~m}$ (LEITE e KLEIN, 1990; IBGE, 1992).

\section{Coleta, tratamento e análise dos dados}

A presente análise foi realizada com base nos dados levantados durante o Projeto Árvore - Censo Verde de Maringá, planejado e executado pelo Centro Universitário de Maringá - CESUMAR. O Projeto Árvore teve como objetivo principal realizar um inventário qualitativo e quantitativo da arborização das vias públicas da cidade de Maringá, abrangendo cerca de $73 \%$ de sua área urbana efetiva e cadastrando em torno de $90 \%$ de sua arborização (SAMPAIO, 2007).

Os levantamentos em campo foram realizados por equipes de alunos do Curso de Ciências Biológicas do Centro Universitário de Maringá (CESUMAR), os quais receberam treinamento teórico e prático para executar a coleta de dados. A coleta de campo teve inicio em março de 2004 e término em agosto de 2005 (SAMPAIO, 2007).

As informações referentes a cada árvore foram cadastradas em aparelhos "palm top" equipados com um programa de cadastramento específico que seguiu as diretrizes dos dados a serem coletados. As informações registradas em campo foram: a) Identificação e localização do registro; b) Identificação da espécie; c) Porte da árvore; d) Qualidade (Fitossanidade); e) Posição de plantio; f) Situação em relação à rede elétrica; g) Situação fenológica; h) Necessidade de manejo (SAMPAIO, 2007).

Dentre estas informações foram apenas utilizados para o presente estudo os dados de identificação das espécies e as quantidades de indivíduos por espécie, enfocando-se a questão das exóticas invasoras utilizadas na arborização de vias públicas de Maringá. 
Para tal foi necessária uma análise de cada espécie amostrada no sentido de verificar sua correta determinação taxonômica, suas origens e limites de ocorrência natural e, por fim, o seu potencial de invasão biológica. Tais averiguações foram realizadas com base em literatura científica e na experiência de campo dos autores. A base dos resultados e discussões do presente estudo foram as informações de procedência e status de invasão de cada espécie, cujas categorias definidas são especificadas a seguir:

\section{a) Categorias de Procedência:}

De acordo com Zalba (2006), é importante salientar que é comum serem usadas apenas fronteiras políticas para considerar uma espécie exótica. No entanto, este critério em muitos casos diverge do correto conceito ecológico, que determina ser exótica qualquer espécie proveniente de um ambiente ou região ecológica diferente. Portanto, espécies dentro de um mesmo país ou estado são podem ser consideradas exóticas se introduzidas em ecossistemas onde não ocorrem naturalmente.

Desta forma, para a definição das categorias de procedência foi considerado apenas o critério ecológico, sendo desconsideradas fronteiras políticas. A seguir são descritas as categorias:

a.1) Exótica Extra Ecossistemas Brasileiros (ex-BR) $\rightarrow$ espécie que não ocorre espontaneamente nos ecossistemas existentes em território brasileiro, sendo oriunda de ecossistemas de outros paises;

a.2) Exótica Extra Ecossistemas Paranaenses (ex-PR) $\rightarrow$ espécie que não ocorre espontaneamente em ecossistemas paranaenses, sendo oriunda de ecossistemas distintos existentes em outros estados do Brasil;

a.3) Exótica Extra Ecossistema de Floresta Estacional Semidecidual Paranaense (exFESPR) $\rightarrow$ espécie que não ocorre espontaneamente dentro dos limites fitogeográficos da Floresta Estacional Semidecidual no Paraná, mas que pode ocorrer em outras tipologias vegetais do Estado ou mesmo em outros estados do Brasil;

a.4) Nativa $\rightarrow$ espécie que ocorre espontaneamente no ecossistema de Floresta Estacional Semidecidual Paranaense, cujos limites fitogeográficos abrangem o município de Maringá.

b) Categorias do Status de Invasão (apenas para as exóticas):

As definições destas categorias foram adaptadas de Zalba (2006), sendo descritas a seguir:

b.1) Introduzida (Int) $\rightarrow$ espécie trazida de outros ambientes ou regiões ecológicas, cujos indivíduos conseguem se desenvolver, mas sem reproduzir-se no novo ambiente onde foram introduzidos; 
b.2) Estabelecida (Est) $\rightarrow$ espécie trazida de outros ambientes ou regiões ecológicas, cujos indivíduos conseguem se reproduzir no ambiente de introdução (no caso, a região de Maringá), podendo ou não se tornar uma invasora;

b.3) Invasora (Inv) $\rightarrow$ espécie trazida de outros ambientes ou regiões ecológicas, cujas populações são capazes de avançar sobre ecossistemas naturais, conservados ou alterados, causando impactos ambientais e sócio-econômicos;

b.4) Desconhecida (Des) $\rightarrow$ espécie da qual ainda não existem registros oficiais e/ou científicos como estabelecida ou invasora, não podendo-se, no entanto, descartar tais possibilidades;

Para o enquadramento das espécies registradas na arborização de vias públicas de Maringá nas categorias de invasão acima descritas foram consideradas informações oficiais e científicas, com prioridade para aquelas de âmbito estadual.

A freqüência das espécies na cidade (\%) foi obtida através da razão entre o número de indivíduos registrados da espécie e o número total de indivíduos registrados no estudo.

\section{RESULTADOS E DISCUSSÃO}

Dentre o montante de 93.261 árvores registradas nas vias públicas de Maringá (SAMPAIO, 2007) foi possível determinar com segurança a taxonomia de 87 espécies distintas pertencentes a 37 famílias botânicas (Tabela 1). As espécies indeterminadas representaram apenas 3,8\% do total de indivíduos levantados.

O número relativamente alto de espécies registradas pode levar a uma impressão precipitada de que a arborização de vias públicas de Maringá apresenta elevada diversidade de espécies sendo, portanto bem planejada e benéfica para o meio ambiente. No entanto, a grande maioria das espécies registradas ( $n=66 / 75,9 \%)$ é representada por exóticas ao ecossistema de Floresta Estacional Semidecidual da região de Maringá. Destas predominam as espécies oriundas de outros países $(n=48)$, as quais não ocorrem espontaneamente nos ecossistemas brasileiros (Figura 1). As demais espécies exóticas ao ecossistema natural de Maringá são procedentes de outros ecossistemas vegetais no próprio Paraná $(n=5)$ e de ecossistemas existentes em outros estados do Brasil $(n=13)$. Assim, apenas 21 das espécies utilizadas na arborização de vias públicas de Maringá são nativas do ecossistema da Floresta Estacional Semidecidual paranaense. 


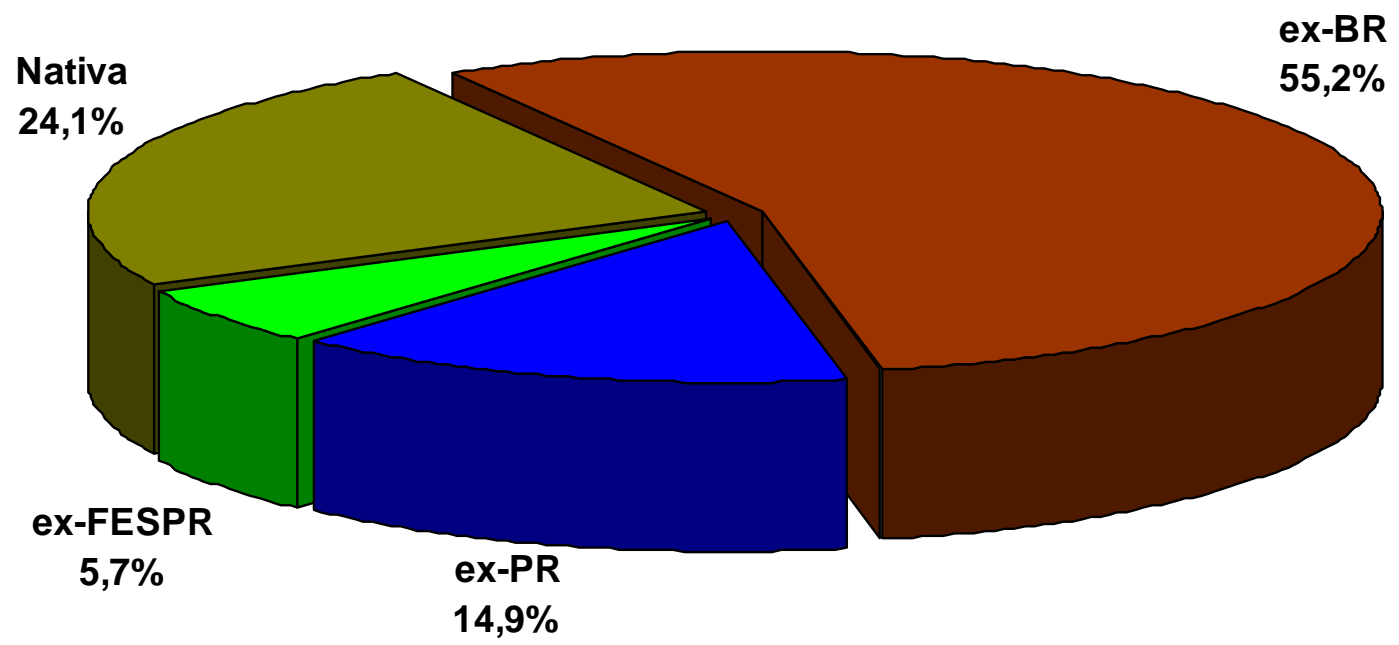

Figura 1 - Distribuição por classes de procedências das espécies registradas na arborização de vias públicas de Maringá em 2005.

Tabela 1 - Lista das espécies registradas na arborização de vias públicas de Maringá em 2005, freqüência da espécie na cidade (Fre.\%), categoria de procedência da espécie (Proced.) e categoria do status de invasão.

\begin{tabular}{|c|c|c|c|c|}
\hline Família / Nome Científico & Nome Comum & Fre.\% & Proced. & Status \\
\hline \multicolumn{5}{|l|}{ ANACARDIACEAE } \\
\hline Astronium graveolens Jacq. & guaritá & 0,001 & nativa & Nat. \\
\hline Mangifera indica L. & mangueira & 1,2 & ex-BR & $\operatorname{lnv}^{2}$ \\
\hline Schinus molle L. & aroeira-salsa & 1,2 & ex-FESPR & Des. \\
\hline Schinus terebinthifolius Raddi & aroeira-vermelha & 0,54 & nativa & Nat. \\
\hline Spondias purpurea L. & ciriguela & 0,048 & ex-BR & Des. \\
\hline \multicolumn{5}{|l|}{ APOCYNACEAE } \\
\hline Aspidosperma polyneuron Müll. Arg. & peroba & 0,066 & nativa & Nat. \\
\hline Nerium oleander L. & espirradeira & 0,22 & ex-BR & Int. \\
\hline Plumeria rubra L. & jasmim-manga & 0,002 & ex-BR & Int. \\
\hline \multicolumn{5}{|l|}{ ARAUCARIACEAE } \\
\hline Araucaria angustifolia (Bertol.) Kuntze & pinheiro-do-Paraná & 0,040 & ex-FESPR & Int. \\
\hline \multicolumn{5}{|l|}{ ARECACEAE } \\
\hline Cocos nucifera L. & coqueiro & 0,11 & ex-PR & Int. \\
\hline Latania lontaroides (Gaertn.) H.E. Moore & palmeira-de-leque & 0,094 & ex-BR & Des. \\
\hline Phoenix dactylifera L. & tamareira & 0,21 & ex-BR & Int. \\
\hline Roystonea oleracea (Jacq.) O.F. Cook & palmeira-imperial & 0,63 & ex-BR & Int. \\
\hline \multicolumn{5}{|l|}{ BIGNONIACEAE } \\
\hline Jacaranda mimosifolia D. Don & jacarandá-mimoso & 2,9 & ex-BR & Int. \\
\hline Spathodea campanulata P. Beauv. & bisnagueira & 0,37 & ex-BR & Est. $^{1,2}$ \\
\hline Tabebuia heptaphylla (Vell.) Toledo & ipê-roxo & 10,3 & nativa & Nat. \\
\hline Tabebuia chrysotricha (Mart. ex DC.) Standl. & ipê-amarelo & 2,0 & ex-FESPR & Des. \\
\hline
\end{tabular}




\begin{tabular}{|c|c|c|c|c|}
\hline Família / Nome Científico & Nome Comum & Fre.\% & Proced. & Status \\
\hline Tabebuia impetiginosa (Mart. ex DC.) Standl. & ipê-rosa & 0,039 & ex-PR & Des. \\
\hline Tabebuia roseoalba (Ridl.) Sandwith & ipê-branco & 1,2 & ex-PR & Des. \\
\hline Tecoma stans (L.) Juss. ex Kunth & amarelinho & 0,001 & ex-BR & Inv. ${ }^{1,2}$ \\
\hline \multicolumn{5}{|l|}{ BOMBACACEAE } \\
\hline Chorisia speciosa A. St.-Hil. & paineira & 0,020 & nativa & Nat. \\
\hline Pachira aquatica Aubl. & castanha-do-brejo & 0,75 & ex-PR & Des. \\
\hline \multicolumn{5}{|l|}{ BORAGINACEAE } \\
\hline Cordia trichotoma (Vell.) Arráb. ex Steud. & louro-pardo & 0,004 & nativa & Nat. \\
\hline \multicolumn{5}{|l|}{ CAESALPINIACEAE } \\
\hline Bauhinia variegata $\mathrm{L}$. & pata-de-vaca-lilás & 2,0 & ex-BR & Int. \\
\hline Caesalpinia echinata Lam. & pau-brasil & 0,31 & ex-PR & Int. \\
\hline Caesalpinia ferrea Mart. & pau-ferro & 0,26 & ex-PR & Int. \\
\hline Caesalpinia peltophoroides Benth. & sibipiruna & 39,2 & ex-PR & Des. \\
\hline Caesalpinia pulcherrima (L.) Sw. & flor-de-pavão & 0,013 & ex-BR & Des. \\
\hline Cassia fistula $\mathrm{L}$. & chuva-de-ouro & 0,20 & ex-BR & Des. \\
\hline Delonix regia (Bojer ex Hook.) Raf. & flamboyant & 1,5 & ex-BR & Int. \\
\hline Holocalyx balansae Micheli & alecrim & 2,7 & nativa & Nat. \\
\hline Hymenaea courbaril L. & jatobá & 0,002 & nativa & Nat. \\
\hline Peltophorum dubium (Spreng.) Taub. & canafístula & 0,083 & nativa & Nat. \\
\hline Schizolobium parahyba (Vell.) S.F. Blake & guapuruvu & 0,028 & ex-FESPR & $\operatorname{lnv}^{2}$ \\
\hline Senna macranthera H.S. Irwin \& Barneby & manduirana & 0,44 & ex-PR & Des. \\
\hline Senna spectabilis H.S. Irwin \& Barneby & são-joão & 0,002 & ex-PR & Des. \\
\hline Tamarindus indica L. & tamarindeiro & 0,002 & ex-BR & Des. \\
\hline Tipuana tipu (Benth.) Kuntze & tipuana & 6,7 & ex-BR & Int. \\
\hline \multicolumn{5}{|l|}{ CHRYSOBALANACEAE } \\
\hline Licania tomentosa (Benth.) Fritsch & oiti & 3,5 & ex-PR & Des. \\
\hline \multicolumn{5}{|l|}{ COMBRETACEAE } \\
\hline Terminalia catappa L. & chapéu-de-sol & 1,2 & ex-BR & Est. $^{1,2}$ \\
\hline \multicolumn{5}{|l|}{ CUPRESSACEAE } \\
\hline Chamaecyparis spp. & cedrinhos & 0,22 & ex-BR & Int. \\
\hline Cupressus Iusitanica Mill. & cipreste & 0,002 & ex-BR & Est. $^{2}$ \\
\hline \multicolumn{5}{|l|}{ EBENACEAE } \\
\hline Diospyros kaki L. f. & caquizeiro & 0,004 & ex-BR & Int. \\
\hline \multicolumn{5}{|l|}{ ERICACEAE } \\
\hline Rhododendron simsii Planch. & azaléia & 0,001 & ex-BR & Int. \\
\hline \multicolumn{5}{|l|}{ FABACEAE } \\
\hline Clitoria fairchildiana R.A. Howard & palheteira & 0,53 & ex-PR & Des. \\
\hline Machaerium stipitatum (DC.) Vogel & sapuva & 0,006 & nativa & Nat. \\
\hline \multicolumn{5}{|l|}{ FAGACEAE } \\
\hline Castanea sativa Mill. & castanha-portuguesa & 0,008 & ex-BR & Int. \\
\hline \multicolumn{5}{|l|}{ LAURACEAE } \\
\hline Nectandra megapotamica (Spreng.) Mez & canelinha & 0,43 & nativa & Nat. \\
\hline
\end{tabular}




\begin{tabular}{|c|c|c|c|c|}
\hline Família / Nome Científico & Nome Comum & Fre.\% & Proced. & Status \\
\hline Persea americana Mill. & abacateiro & 0,29 & ex-BR & Est. $^{3}$ \\
\hline \multicolumn{5}{|l|}{ LYTHRACEAE } \\
\hline Lagerstroemia indica L. & extremosa & 0,41 & ex-BR & Int. \\
\hline \multicolumn{5}{|l|}{ MAGNOLIACEAE } \\
\hline Michelia champaca L. & magnólia & 0,23 & ex-BR & Int. \\
\hline \multicolumn{5}{|l|}{ MALPIGHIACEAE } \\
\hline Malpighia emarginata Sessé \& Moc. ex DC. & acerola & 0,001 & ex-BR & Int. \\
\hline \multicolumn{5}{|l|}{ MALVACEAE } \\
\hline Hibiscus rosa-sinensis L. & hibisco & 0,33 & ex-BR & Int. \\
\hline \multicolumn{5}{|l|}{ MELASTOMATACEAE } \\
\hline Tibouchina mutabilis (Vell.) Cogn. & quaresmeira & 0,002 & ex-FESPR & Des. \\
\hline Tibouchina granulosa (Desr.) Cogn. & quaresmeira & 0,96 & ex-PR & Int. \\
\hline \multicolumn{5}{|l|}{ MELIACEAE } \\
\hline Cedrela fissilis Vell. & cedro-rosa & 0,050 & nativa & Nat. \\
\hline Melia azedarach L. & cinamomo & 0,23 & ex-BR & Inv. ${ }^{1,2}$ \\
\hline \multicolumn{5}{|l|}{ MIMOSACEAE } \\
\hline Calliandra brevipes Benth. & caliandra & 0,088 & nativa & Nat. \\
\hline Enterolobium contortisiliquum (Vell.) Morong & timbaúva & 0,004 & nativa & Nat. \\
\hline Leucaena leucocephala (Lam.) de Wit & leucena & 0,32 & ex-BR & Inv. ${ }^{1,2}$ \\
\hline Parapiptadenia rigida (Benth.) Brenan & gurucaia & 0,011 & nativa & Nat. \\
\hline \multicolumn{5}{|l|}{ MORACEAE } \\
\hline Artocarpus heterophyllus Lam. & jaqueira & 0,12 & ex-BR & $\operatorname{lnv}^{2}$ \\
\hline Ficus benjamina L. & ficus & 2,4 & ex-BR & Int. \\
\hline Ficus guaranitica Chodat & figueira & 0,083 & nativa & Nat. \\
\hline Morus nigra L. & amoreira & 0,032 & ex-BR & $\operatorname{lnv} .^{1,2}$ \\
\hline \multicolumn{5}{|l|}{ MYRTACEAE } \\
\hline Eucaliptus spp. & eucalipto & 0,040 & ex-BR & Inv. ${ }^{1,2}$ \\
\hline Eugenia uniflora L. & pitangueira & 0,17 & nativa & Nat. \\
\hline Myrciaria trunciflora O. Berg & jaboticabeira & 0,032 & nativa & Nat. \\
\hline Psidium guajava $\mathrm{L}$. & goiabeira & 0,28 & ex-BR & $\operatorname{lnv}^{1,2}$ \\
\hline Syzygium cumini (L.) Skeels & jambolão & 0,11 & ex-BR & $\operatorname{lnv}^{1,2}$ \\
\hline \multicolumn{5}{|l|}{ NYCTAGINACEAE } \\
\hline Bougainvillea glabra Choisy & primavera & 0,023 & nativa & Nat. \\
\hline \multicolumn{5}{|l|}{ OLEACEAE } \\
\hline Ligustrum lucidum W.T. Aiton & alfeneiro & 2,8 & ex-BR & $\operatorname{lnv}^{1,2}$ \\
\hline \multicolumn{5}{|l|}{ PHYTOLACCACEAE } \\
\hline Gallesia integrifolia (Spreng.) Harms & pau-d’álho & 0,002 & nativa & Nat. \\
\hline \multicolumn{5}{|l|}{ PINACEAE } \\
\hline Pinus spp. & pinus & 0,016 & ex-BR & Inv..$^{1,2}$ \\
\hline \multicolumn{5}{|l|}{ PROTEACEAE } \\
\hline Grevillea robusta A. Cunn. ex R. Br. & grevílea & 2,2 & ex-BR & Est. $^{2}$ \\
\hline
\end{tabular}




\begin{tabular}{|c|c|c|c|c|}
\hline Família / Nome Científico & Nome Comum & Fre.\% & Proced. & Status \\
\hline Punica granatum $\mathrm{L}$. & romã & 0,091 & ex-BR & Int. \\
\hline \multicolumn{5}{|l|}{ RHAMNACEAE } \\
\hline Colubrina glandulosa Perkins & sobrasil & 0,013 & nativa & Nat. \\
\hline Hovenia dulcis Thunb. & uva-do-japão & 0,047 & ex-BR & Inv. ${ }^{1,2}$ \\
\hline \multicolumn{5}{|l|}{ ROSACEAE } \\
\hline Eriobotrya japonica (Thunb.) Lindl. & nespereira & 0,055 & ex-BR & Inv. ${ }^{1,2}$ \\
\hline Prunus persica (L.) Batsch & pessegueiro & 0,003 & ex-BR & Int. \\
\hline \multicolumn{5}{|l|}{ RUTACEAE } \\
\hline Citrus aurantium $\mathrm{L}$. & laranjeira & 0,025 & ex-BR & Inv. ${ }^{1,2}$ \\
\hline Citrus limon (L.) Burm. f. & limoeiro & 0,25 & ex-BR & Inv. ${ }^{1,2}$ \\
\hline Citrus reticulata Blanco & mexerica & 0,019 & ex-BR & Est. $^{3}$ \\
\hline Murraya paniculata (L.) Jack & falsa-murta & 3,2 & ex-BR & Int. \\
\hline \multicolumn{5}{|l|}{ SALICACEAE } \\
\hline Populus nigra L. & álamo & 0,001 & ex-BR & Int. \\
\hline \multicolumn{5}{|l|}{ SAPINDACEAE } \\
\hline Talisia esculenta (A. St.-Hil.) Radlk. & pitomba & 0,003 & ex-PR & Des. \\
\hline \multicolumn{5}{|l|}{ SOLANACEAE } \\
\hline Cestrum nocturnum L. & dama-da-noite & 0,002 & ex-BR & Des. \\
\hline INDETERMINADAS & & 3,8 & - & - \\
\hline
\end{tabular}

Fonte: ${ }^{1}$ IAP (2007); ${ }^{2}$ INSTITUTO HÓRUS (2008a); ${ }^{3}$ DAHER et al. (2007).

No que se refere à procedência das espécies registradas, a maior parte $(\mathrm{N}=34$ I $39,1 \%$ ) tem sua origem fora do continente americano (Tabela 2). Este é o caso de várias espécies muito apreciadas para o paisagismo no Brasil, como Murraya paniculata, Ligustrum lucidum, Ficus benjamina, Terminalia catappa, Lagerstroemia indica, Hibiscus rosa-sinensis, Melia azedarach, Michelia champaca, Nerium oleander, Phoenix dactylifera, Delonix regia, Spathodea campanulata, Rhododendron simsii e Grevillea robusta. Muitas destas espécies, devido a sua intensa utilização, são muitas vezes consideradas como espécies nativas pela comunidade em geral. As demais espécies registradas ( $n=53$ / 60,9\%) são oriundas do continente americano. Parte destas ( $n=14 / 16,1 \%)$ não ocorre nos ecossistemas brasileiros, distribuindo-se por outras regiões ecológicas da América, e a parte restante é caracterizada por espécies nativas dos ecossistemas brasileiros ( $n=39$ / 44,8\%).

Salienta-se que somente 21 espécies $(24,1 \%)$ se enquadram como nativas do ecossistema de Floresta Estacional Semidecidual Paranaense, sendo portanto as únicas de fato nativas do município de Maringá.

Tabela 2 - Regiões de origem das espécies registradas na arborização de vias públicas de Maringá em 2005. 


\begin{tabular}{|c|c|c|}
\hline Região de origem & Espécies & Fonte \\
\hline África & $\begin{array}{l}\text { Delonix regia, Latania lontaroides, Phoenix } \\
\text { dactylifera, Spathodea campanulata, } \\
\text { Tamarindus indica }\end{array}$ & $\begin{array}{l}\text { LORENZI (1996), LORENZI } \\
\text { (2003), LORENZI et al. } \\
\text { (2006) }\end{array}$ \\
\hline América Central & $\begin{array}{l}\text { Caesalpinia pulcherrima, Cestrum nocturnum, } \\
\text { Cupressus lusitanica, Leucaena leucocephala, } \\
\text { Malpighia emarginata, Persea americana, } \\
\text { Plumeria rubra, Psidium guajava, Roystonea } \\
\text { oleracea, Spondias purpurea, Tecoma stans }\end{array}$ & $\begin{array}{l}\text { LORENZI (1996), LORENZI } \\
\text { e SOUZA (1999), LORENZI } \\
\text { (2003), LORENZI et al. } \\
\text { (2006), INSTITUTO } \\
\text { HÓRUS (2008a) }\end{array}$ \\
\hline América do Norte & Pinus spp. & $\begin{array}{lr}\text { LORENZI } & (2003), \\
\text { INSTITUTO } & \text { HÓRUS } \\
(2008 a) & \\
\end{array}$ \\
\hline América do Sul & Jacaranda mimosifolia, Tipuana tipu & LORENZI (2003) \\
\hline Ásia & $\begin{array}{l}\text { Artocarpus heterophyllus, Bauhinia variegata, } \\
\text { Cassia fistula, Citrus aurantium, Citrus limon, } \\
\text { Citrus reticulata, Diospyros kaki, Eriobotrya } \\
\text { japonica, Ficus benjamina, Hibiscus rosa- } \\
\text { sinensis, Hovenia dulcis, Lagerstroemia } \\
\text { indica, Ligustrum lucidum, Mangifera indica, } \\
\text { Melia azedarach, Michelia champaca, Morus } \\
\text { nigra, Murraya paniculata, Prunus persica, } \\
\text { Punica granatum, Rhododendron simsii, } \\
\text { Syzygium cumini, Terminalia catappa }\end{array}$ & $\begin{array}{l}\text { LORENZI e SOUZA (1999), } \\
\text { LORENZI (2003), LORENZI } \\
\text { et al.(2006) }\end{array}$ \\
\hline Europa & $\begin{array}{l}\text { Castanea sativa, Chamaecyparis spp., Nerium } \\
\text { oleander, Populus nigra }\end{array}$ & $\begin{array}{l}\text { LORENZI e SOUZA (1999), } \\
\text { LORENZI (2003), LORENZI } \\
\text { et al.(2006) }\end{array}$ \\
\hline Oceania & Eucaliptus spp., Grevillea robusta & LORENZI (2003) \\
\hline $\begin{array}{l}\text { Brasil } \\
\text { Nordeste }\end{array}$ & Cocos nucifera, Senna spectabilis & $\begin{array}{l}\text { LORENZI (1992), LORENZI } \\
\text { et al.(2006) }\end{array}$ \\
\hline $\begin{array}{l}\text { Brasil } \\
\text { Sudeste e } \\
\text { Nordeste }\end{array}$ & 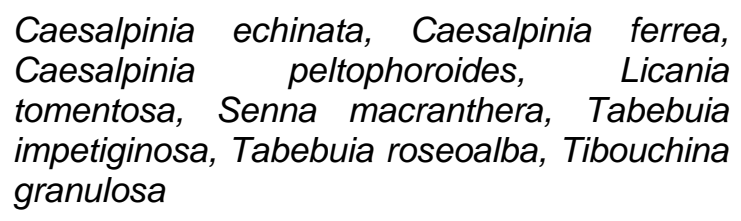 & LORENZI (1992) \\
\hline $\begin{array}{l}\text { Brasil } \\
\text { Norte }\end{array}$ & $\begin{array}{l}\text { Clitoria fairchildiana, Pachira aquatica, Talisia } \\
\text { esculenta }\end{array}$ & LORENZI (1992) \\
\hline $\begin{array}{l}\text { Paraná } \\
\text { Flo. Ombrófila Densa }\end{array}$ & $\begin{array}{l}\text { Schizolobium parahyba, } \\
\text { chrysotricha, Tibouchina mutabilis }\end{array}$ & $\begin{array}{l}\text { LORENZI } \\
\text { SOCIEDADE } \\
(2008)\end{array}$ \\
\hline $\begin{array}{l}\text { Paraná } \\
\text { Flo. Ombrófila Mista }\end{array}$ & Araucaria angustifolia, Schinus molle & $\begin{array}{l}\text { LORENZI } \\
\text { SOCIEDADE } \\
(2008)\end{array}$ \\
\hline $\begin{array}{l}\text { Paraná } \\
\text { Flo. Estacional } \\
\text { Semidecidual } \\
\text { (nativas na área em } \\
\text { estudo) }\end{array}$ & $\begin{array}{lrr}\text { Aspidosperma polyneuron, } & \text { Astronium } \\
\text { graveolens, Bougainvillea glabra, Calliandra } \\
\text { brevipes, Cedrela fissilis, Chorisia speciosa, } \\
\text { Colubrina glandulosa, Cordia trichotoma, } \\
\text { Enterolobium contortisiliquum, Eugenia } \\
\text { uniflora, Ficus guaranitica, Gallesia } \\
\text { integrifolia, Holocalyx balansae, Hymenaea } \\
\text { courbaril, Machaerium stipitatum, Myrciaria } \\
\text { trunciflora, Nectandra megapotamica, } \\
\text { Parapiptadenia rigida, Peltophorum dubium, } \\
\text { Schinus terebinthifolius, Tabebuia heptaphylla }\end{array}$ & $\begin{array}{l}\text { LORENZI } \\
\text { SOCIEDADE } \\
\text { (2008) }\end{array}$ \\
\hline
\end{tabular}


Dentre as espécies americanas "extra ecossistemas brasileiros" existem várias muito populares no Brasil, sendo também muitas vezes consideradas erroneamente como nativas. Neste caso se enquadram Caesalpinia pulcherrima, Cupressus lusitanica, Leucaena leucocephala, Malpighia emarginata, Persea americana, Psidium guajava, Pinus spp. e Tecoma stans, entre outras. Destaque deve ser feito às espécies Jacaranda mimosifolia e Tipuana tipu, ambas ocorrentes em países vizinhos ao Brasil como Argentina, Paraguai e Bolívia, as quais são freqüentemente consideradas nativas do Brasil, ainda que não tenham sido encontrados registros destas espécies em florestas nativas do País.

No âmbito das espécies brasileiras "extra ecossistemas paranaenses" existem aquelas procedentes de ecossistemas mais longínquos das regiões norte e nordeste do País como Clitoria fairchildiana, Talisia esculenta, Pachira aquática, Cocos nucifera e Senna spectabilis. Também nesta categoria se enquadram espécies que ocorrem desde o nordeste até o sudeste do Brasil, como Licania tomentosa, Tibouchina granulosa, Caesalpinia echinata, Caesalpinia ferrea, Caesalpinia peltophoroides, Tabebuia impetiginosa, Tabebuia roseoalba e Senna macranthera.

Por fim, também existe o grupo de espécies que ocorre naturalmente no Paraná, mas em outros ecossistemas, enquadradas como "extra ecossistema de Floresta Estacional Semidecidual paranaense". É o caso de Araucaria angustifolia, Schinus molle, Schizolobium parahyba, Tabebuia chrysotricha e Tibouchina mutabilis.

No que refere à freqüência das espécies na cidade, os resultados totais obtidos no presente estudo demonstraram que a grande maioria $(n=76.036 / 81,5 \%)$ das árvores das vias públicas de Maringá se enquadram como "não nativas do ecossistema Floresta Estacional Semidecidual paranaense" (categorias ex-BR, ex-PR e ex-FESPR), ou seja, exóticas ao ecossistema regional, considerando os limites ecológicos de ocorrência.

No entanto, se fosse utilizado o critério tradicional, que considera apenas fronteiras políticas, apenas 31\% $(n=28.910)$ das árvores se enquadrariam como exóticas (no caso, ao Brasil) e $65,2 \%(n=60.802)$ se enquadrariam como nativas (do território brasileiro). A predominância de nativas do Brasil se deve a grande quantidade de árvores de Caesalpinia peltophoroides ( $n=36.570 / 39,2 \%$ ). Inventários realizados em outras cidades brasileiras demonstram o predomínio das espécies exóticas (sempre consideram fronteiras políticas) sobre as nativas (sempre consideram as nativas do Brasil como um todo). Em Campina Grande - PB, Dantas e Souza (2004) registraram freqüências de 67,2\% para árvores exóticas e 32,8\% para nativas do Brasil. Na outra extremidade do País, em Lageado - RS, Ruschel e Leite (2002) encontraram valores mais equilibrados: $53,6 \%$ de exóticas e 46,4\% de nativas. Por fim, em Pato Branco - PR, Silva et al. (2007), registraram valores muito próximos aos de Lageado: 53,2\% de exóticas e 46,8\% de nativas. 
Com base no cenário da composição florística da arborização das vias públicas de Maringá é importante salientar que nem toda espécie exótica traz necessariamente prejuízos ambientais e/ou sociais. É certo que o ideal seria a utilização predominante de espécies nativas da região, não só por motivos ecológicos como também para valorizar a riqueza florística regional. No entanto, existem espécies exóticas que se mantêm contidas nos locais onde foram plantadas sem tornarem-se invasoras. Este é o caso das espécies categorizadas como introduzidas.

Dentre as espécies "não nativas do ecossistema Floresta Estacional Semidecidual paranaense" (categorias ex-BR, ex-PR e ex-FESPR), aquelas que se enquadram apenas como "Introduzida" ( $n=26$ / 29,9\%), e que reconhecidamente não têm a capacidade de se reproduzir e dispersar nesta região, podem ser toleradas na arborização de vias públicas, desde que tenham características muito apreciáveis para este fim. Dentre estas pode-se citar Lagerstroemia indica, Jacaranda mimosifolia, Hibiscus rosa-sinensis, Delonix regia, Caesalpinia ferrea e Caesalpinia echinata.

Numa situação mais distinta estão aquelas espécies "não nativas do ecossistema Floresta Estacional Semidecidual paranaense" (categorias ex-BR, ex-PR e ex-FESPR) enquadradas como "Estabelecida" ( $n=6 / 6,9 \%)$. Estas têm capacidade de se reproduzir e possivelmente de se dispersar além dos locais onde foram plantadas podendo, em alguns casos, tornarem-se invasoras. Neste grupo foram reunidas apenas as espécies Terminalia catappa, Spathodea campanulata, Cupressus Iusitanica, Persea americana, Grevillea robusta e Citrus reticulata. Estas foram assim categorizadas por apresentarem registros de reprodução e dispersão na própria região de Maringá ou em outras regiões do Paraná e de São Paulo (DAHER et al., 2007; INSTITUTO HÓRUS, 2008a), sendo, portanto, exóticas menos aconselháveis para a arborização de vias públicas por apresentarem potencial de invasão.

O mesmo cuidado deve ser tomado com as espécies categorizadas como "Desconhecida" ( $n=18$ / 20,7\%), das quais não se têm informações sobre o potencial de invasão. Somente após a confirmação de suas características de reprodução e dispersão, através de ensaios científicos, é que poderá ser indicada a sua utilização ou não em arborização urbana.

Por fim, destacam-se as espécies "não nativas do ecossistema Floresta Estacional Semidecidual paranaense" (categorias ex-BR, ex-PR e ex-FESPR) enquadradas na categoria "Invasora", as quais totalizam 18,4\% $(n=16)$ do total de espécies. Destas, 12 fazem parte da "Lista Oficial de Espécies Exóticas Invasoras para o Estado do Paraná" (IAP, 2007). A listagem do "Informe sobre Espécies Invasoras que afetam o Ambiente Terrestre" (INSTITUTO HÓRUS, 2008a; MMA, 2006) abrange 15 destas espécies, em alguns casos, com registros próximos ao município de Maringá. 
Como exemplo pode-se citar Leucaena leucocephala, que figura no informe com invasões biológicas em Campo Mourão e Ibiporã (INSTITUTO HÓRUS, 2008b); Melia azedarach, com invasões registradas em Cianorte e no Parque Nacional de Ilha Grande, Rio Paraná (INSTITUTO HÓRUS, 2008c); e Tecoma stans, espécie muito agressiva com invasões registradas em muitos municípios do interior do Paraná (INSTITUTO HÓRUS, 2008d).

Desta forma, 5.146 árvores (5,5\%) que compõe a atual arborização de vias públicas de Maringá pertencem a estas espécies exóticas invasoras sendo bastante aconselhável sua substituição gradativa por espécies nativas da Floresta Estacional Semidecidual paranaense ou, em último caso, espécies exóticas sem potencial de invasão. As invasoras com maior potencial de prejuízos ambientais e/ou sociais, considerando registros de invasões no Paraná, são Hovenia dulcis, Leucaena leucocephala, Melia azedarach e Tecoma stans (INSTITUTO HÓRUS, 2008b, 2008c, 2008d, 2008e).

Hovenia dulcis e Melia azedarach tem grande facilidade de dispersão através de florestas ciliares sendo que em alguns locais no Paraná já constituem o estrato predominante de florestas aluviais, tomando agressivamente o espaço de diversas espécies nativas (INSTITUTO HÓRUS, 2008c, 2008e).

Leucaena leucocephala e Tecoma stans caracterizam-se por colonizar muito rapidamente clareiras e áreas em estágios iniciais de sucessão vegetal, formando comunidades muito densas e impedindo o desenvolvimento das florestas nativas. Tecoma stans também traz prejuízos para a agropecuária por ser de difícil erradicação e infestar intensamente pastagens e culturas agrícolas em certas regiões do Paraná (BREDOW, PEDROSA-MACEDO E VITORINO, 2004; INSTITUTO HÓRUS, 2008b, 2008d).

As demais espécies exóticas invasoras também apresentam importância mas tendem a ser menos agressivas que as quatro espécies acima descritas, para a região de Maringá. Artocarpus heterophyllus, Citrus aurantium, Citrus limon, Eriobotrya japonica, Eucaliptus spp., Ligustrum lucidum, Mangifera indica, Morus nigra, Psidium guajava e Schizolobium parahyba certamente se dispersam a partir da arborização de vias públicas para comunidades nativas próximas e/ou áreas degradadas, no entanto, em menor grau ou rapidez, tomando-se para tal julgamento o conjunto de registros reunidos pelo Instituto Hórus (2008a) e também a experiência de campo dos autores do presente artigo.

A importância das espécies exóticas invasoras na arborização de vias públicas em Maringá pode ser ressaltada analisando-se somente o grupo de 43 espécies cujo número de indivíduos registrados foi superior a 100 (Figura 2), as quais provavelmente devem ser todas oriundas de plantios oficiais da prefeitura, e não de introduções domésticas ocasionais. 


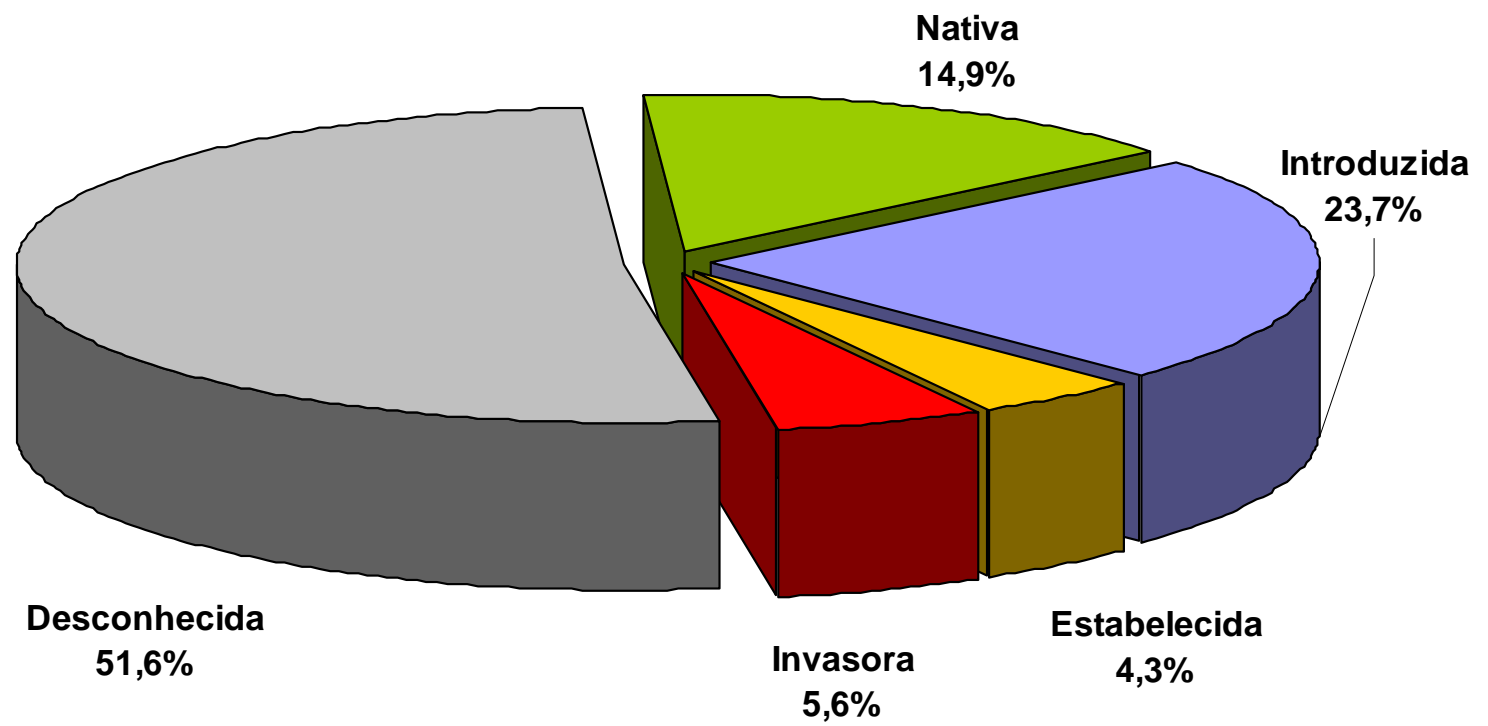

Figura 2 - Distribuição por classes do status de invasão das 43 espécies mais freqüentes na arborização de vias públicas de Maringá em 2005.

Destas 43 espécies, que representam 95,0\% $(n=88.577)$ do total de árvores registradas, apenas 5 (13.220 árvores) são nativas do ecossistema Floresta Estacional Semidecidual, sendo 17 (20.971 árvores) introduzidas, 4 (3.778 árvores) estabelecidas, 8 (4.919 árvores) invasoras e as espécies restantes (45.689 árvores) enquadradas no status de invasão "Desconhecida".

\section{CONCLUSÕES}

A comparação dos dados de freqüência de árvores em Maringá obtidos através de critérios diferenciados para definição de exóticas e nativas demonstram a limitação do critério tradicional (que utiliza apenas fronteiras políticas nacionais) e a importância de se utilizar o critério ecológico (que considera limites de ocorrência dos ecossistemas). Considerando o critério tradicional poderia se ter uma falsa impressão de que a arborização de Maringá atende aos objetivos da conservação ambiental e da biodiversidade, já que apenas $31,0 \%$ das árvores seriam consideradas exóticas. No entanto, a realidade é que 81,5\% das árvores existentes na arborização de vias públicas de Maringá são exóticas ao ecossistema de Floresta Estacional Semidecidual paranaense, que abrange a cidade.

Além de predominar no número de indivíduos, as espécies "não nativas do ecossistema Floresta Estacional Semidecidual paranaense" (categorias ex-BR, ex-PR e exFESPR) também se destacaram pela riqueza de espécies, que representou 75,9\% do total.

Destacou-se sobretudo a quantidade de espécies exóticas invasoras existentes, em especial Hovenia dulcis, Leucaena leucocephala, Melia azedarach e Tecoma stans, que 
apresentam grande potencial invasor já registrado por outros pesquisadores em regiões próximas. Estas espécies, caso não sejam controladas, causarão graves prejuízos ambientais e sócio-econômicos às regiões urbana e metropolitana de Maringá.

A dispersão destas espécies incorrerá na modificação das comunidades florestais da região, sendo que as exóticas invasoras tenderão a ocupar o espaço de espécies nativas acarretando desequilíbrios ecológicos e, em médio ou longo prazo, redução na biodiversidade regional.

É de extrema importância que as exóticas invasoras sejam, de forma planejada e gradativa, substituídas por espécies preferencialmente nativas da região fitoecológica local na arborização de vias públicas. Estas devem, portanto, ser priorizadas nos planejamentos de manejo da arborização. É sobretudo importante que os técnicos responsáveis e a própria população sejam conscientizados sobre a problemática destas espécies invasoras evitando desta forma que ocorram novas introduções que possam mais tarde acarretar invasão biológica.

Aumentar a freqüência de espécies nativas da Floresta Estacional Semidecidual paranaense na arborização de vias públicas de Maringá significa viabilizar uma arborização ecológica, valorizando espécies e ecossistemas autóctones.

\section{REFERÊNCIAS}

BARROS, Z. X.; TORNERO, M. T.; STIPP, N. A. F.; CARDOSO, L. G.; POLLO, R. A. Estudo da Adequação do Uso do Solo, no Município de Maringá - PR, Utilizando-se de Geoprocessamento. Eng. Agríc., Jaboticabal, v.24, n.2, p.436-444, ago. 2004.

BREDOW, E. A.; PEDROSA-MACEDO, J. H.; VITORINO, M. D. Amarelinho Tecoma Stans (L.) Jussieu ex. Kunth (Bignoniaceae) - uma ornamental multiuso ou uma plástica invasora. In: BREDOW, E. A.; PEDROSA-MACEDO, J. H. (org.). Princípios e Rudimentos do Controle Biológico de Plantas - Coletânea. Curitiba: [s.n.], p. 51-105, 2004

DAHER, G. A. et al. Importância dos remanescentes florestais de Embu (SP, Brasil) para a conservação da flora regional. Biota Neotropica, Campinas, v.7, n.3, p. 145-161, set. 2007.

DANTAS, I. C.; SOUZA, C. M. C. Arborização urbana na cidade de Campina Grande - PB: Inventário e suas espécies. Revista de Biologia e Ciências da Terra, Campina Grande, v.4, n.2, dez. 2004. 
IAP - INSTITUTO AMBIENTAL DO PARANÁ. Portaria IAP nº 074, de 19 de abril de 2007. Reconhece a Lista Oficial de Espécies Exóticas Invasoras para o Estado do Paraná, estabelece normas de controle e dá outras providências. Disponível em < http://www.institutohorus.org.br/download/marcos_legais/Portaria_IAP_074.pdf>. Acesso em 03 dez 2007.

IBGE. Manual Técnico da Vegetação Brasileira. Rio de Janeiro: Fundação Instituto Brasileiro de Geografia e Estatística - IBGE, 1992. 92 p.

INSTITUTO HÓRUS DE DESENVOLVIMENTO E CONSERVAÇÃO AMBIENTAL. Espécies Exóticas Invasoras: Fichas Técnicas. 2008. Disponível em: <http://www.institutohorus.org.br/index.php?modulo=fichasTecnicas>. Acesso em 07 jun 2008a.

INSTITUTO HÓRUS DE DESENVOLVIMENTO E CONSERVAÇÃO AMBIENTAL. Leucaena leucocephala. 2008.2 Disponível em: <http://www.institutohorus.org.br/download/fichas/Leucaena_leucocephala.htm>. Acesso em 07 jun 2008b.

INSTITUTO HÓRUS DE DESENVOLVIMENTO E CONSERVAÇÃO AMBIENTAL. Melia azedarach. 2008.2 Disponível em: $<$ http://www.institutohorus.org.br/download/fichas/Melia_azedarach.htm>. Acesso em 07 jun 2008c.

INSTITUTO HÓRUS DE DESENVOLVIMENTO E CONSERVAÇÃO AMBIENTAL. Tecoma stans. $2008 . \quad$ Disponível em: <http://www.institutohorus.org.br/download/fichas/Tecoma_stans.htm>. Acesso em 07 jun 2008d.

INSTITUTO HÓRUS DE DESENVOLVIMENTO E CONSERVAÇÃO AMBIENTAL. Hovenia dulcis. 2008.

Disponível em: $<$ http://www.institutohorus.org.br/download/fichas/Hovenia_dulcis.htm>. Acesso em 07 jun 2008e.

INSTITUTO DE RECURSOS MUNDIAIS; UNIÃO MUNDIAL PARA A NATUREZA; PROGRAMA DAS NAÇÕES UNIDAS PARA O MEIO AMBIENTE. A estratégia global da biodiversidade - diretrizes de ação para estudar, salvar e usar de maneira sustentável e 
justa a riqueza biótica da Terra. Curitiba: World Resources Institute / Fundação O Boticário de Proteção à Natureza, 1992. 232 p.

LEITE, P.; KLEIN, R. M. Vegetação. In: IBGE. Geografia do Brasil: região Sul. v.2. Rio de Janeiro: Instituto Brasileiro de Geografia e Estatística - IBGE, p. 113-150, 1990.

LORENZI, H. Árvores Brasileiras - Manual de identificação e cultivo de plantas arbóreas nativas do Brasil. Nova Odessa: Editora Plantarum, 1992. 352 p.

LORENZI, H. Palmeiras no Brasil: nativas e exóticas. Nova Odessa: Editora Plantarum, 1996. 303 p.

LORENZI, H.; SOUZA, H. M (de). Plantas Ornamentais no Brasil: arbustivas, herbáceas e trepadeiras. Nova Odessa: Instituto Plantarum, 1999. 1088 p.

LORENZI, H. et al. Árvores Exóticas do Brasil: Madeireiras, Ornamentais e Aromáticas. Nova Odessa: Instituto Plantarum, 2003. 382 p.

LORENZI, H. et al. Frutas Brasileiras e Exóticas Cultivadas. Nova Odessa: Instituto Plantarum, 2006. 640 p.

MAACK, R. Geografia física do Estado do Paraná. Curitiba: BADEP, 1968. 350 p.

MMA - MINISTÉRIO DO MEIO AMBIENTE. Espécies Exóticas Invasoras: Situação Brasileira. Brasília: Ministério do Meio Ambiente, Secretaria de Biodiversidade e Florestas, 2006. $23 \mathrm{p}$

PITELLI, R. A. Plantas Exóticas Invasoras. In: BARBOSA, L. M.; SANTOS JR, N. A. dos (orgs.). A botânica no Brasil: pesquisa, ensino e políticas públicas ambientais. São Paulo: Sociedade Botânica do Brasil, p. 409-412, 2007.

RUSCHEL, D.; LEITE, S. L. C. Arborização Urbana em uma Área da Cidade de Lajeado, Rio Grande do Sul, Brasil. Caderno de Pesquisa Sér. Bio, Santa Cruz do Sul, v.14, n.1, p. 724, jun. 2002.

SAMPAIO, A. C. F. Análise da Arborização de Vias Públicas das Principais Zonas do Plano Piloto de Maringá-PR. 2006. 117 p. Dissertação. (Mestrado em Geografia) Universidade Estadual de Maringá, Maringá, 2006. 
SAMPAIO, A. C. F. Relatório Final Projeto Árvore - Censo Verde de Maringá-PR. Maringá: CESUMAR, 2007. 85 p.

SILVA, L. M. et al. Arborização de Vias Públicas e a Utilização de Espécies Exóticas: o Caso do Bairro Centro de Pato Branco/PR. Scientia Agraria, Curitiba, v.8, n.1, p.47-53, 2007.

SOCIEDADE CHAUÁ. FLORAPARANÁ - Lista Preliminar de Espécies Vegetais do Paraná. 2008. Disponível em: <http://www.chaua.org.br/?q=fsdrp>. Acesso em 07 jun 2008.

VELOSO, H. P.; GÓES-FILHO, L. Fitogeografia brasileira - classificação fisionômicoecológica da vegetação neotropical. Boletim Técnico Projeto RADAMBRASIL - Série Vegetação, Salvador, n.1, p. 1-80, 1982.

ZALBA, S. M. Introdução às Invasões Biológicas - Conceitos e Definições. In: BRAND, K. et al. América do Sul invadida. A crescente ameaça das espécies exóticas invasoras. Cape Town: Programa Global de Espécies Invasoras - GISP, p. 4-5, 2006.

ZILLER, S. R. A Estepe Gramíneo-Lenhosa no segundo planalto do Paraná: diagnóstico ambiental com enfoque à contaminação biológica. 2000. 268 p. Tese. (Doutorado em Engenharia Florestal) Universidade Federal do Paraná, Curitiba, 2000. 